\title{
Topografia, morfologia e irrigação do Baço em Trachemys scripta elegans (WIED, 1838)
}

Marcelo Domingues de FARIA ${ }^{1}$ Alan Peres Ferraz de MELO ${ }^{2}$

\section{Correspondência para:}

Prof. Dr. Alan Peres Ferraz de Melo

Rua Yvette Gabriel Atique, 45 -

bairro Boa Vista-São José do Rio Preto-SP CEP15025-400

Recebido para publicação: 21/10/2003 Aprovado para publicação: 27/03/2007

\author{
1- Pós-graduando da Faculdade de Medicina Veterinária e Zootecnia da \\ Universidade de São Paulo, São Paulo - SP \\ 2- Centro Universitário de Rio Preto, São José do Rio Preto - SP
}

\section{Resumo}

Utilizou-se vinte tartarugas da espécie Trachemys scripta elegans, sendo duas fêmeas jovens, quatro fêmeas adultas, oito machos jovens e seis machos adultos. Inicialmente, retirou-se o plastrão, isolando-se o coração e, já na aorta descendente, introduziu-se uma cânula antes da bifurcação da aorta para injeção de solução de látex corado com pigmento vermelho para identificarmos as artérias com maior precisão. Após a injeção, os animais foram colocados em solução aquosa de formaldeído $20 \%$ por período não inferior a 72 horas e, posteriormente, dissecamos as artérias responsáveis pela irrigação do baço. Observou-se em 30\% dos casos, o baço posicionado caudalmente ao cólon transverso e, em $70 \%$, cranialmente ao mesmo, mas sempre apoiado neste segmento intestinal. Com relação à irrigação do baço, observou-se que em 95\% dos casos, o maior aporte sangüíneo era proveniente da artéria mesentérica cranial, onde apenas $30 \%$ dos animais apresentavam irrigação somente pela artéria lienal; já em 40\% apresentavam irrigação pela artéria lienal e pequenos ramos da artéria cólica esquerda. Em 5\% dos casos era irrigado pela artéria lienal e por um único ramo emitido por uma das artérias jejunais, 5\% eram irrigados pela artéria lienal e por um ramo da artéria pancreaticaduodenal cranial e por uma artéria que tinha origem no tronco comum das artérias jejunais; $15 \%$ dos animais tinham seu baço irrigado pela artéria lienal e por ramos da artéria pancreaticaduodenal cranial. Em 5\% dos animais observamos o baço sendo irrigado apenas por ramificações da artéria cólica esquerda.

\section{Introdução}

A Trachemys scripta elegans é originária da América do Norte e é encontrada desde a Virgínia até a Flórida e do oeste até o Kansas, Oklahoma, Texas e Novo México. Esta espécie apresenta listras avermelhadas ou alaranjadas na região atrás dos olhos; os jovens apresentam a carapaça e a pele variando de verde-amarelado a verde escuro com listras, e a cor dos adultos perde o tom vivo e fica verde-oliva. A carapaça é oval e achatada em cima, com plastrão amarelo com manchas circulares escuras. Indivíduos adultos medem entre 13 e $29 \mathrm{~cm}$ de comprimento de carapaça. Estes animais são criados no Brasil em cativeiros com o
Palavras-chave:

Baço. Trachemys scripta elegans. Topografia. Morfologia. Irrigação. objetivo de servirem como "pets" nas lojas de animais.

Optou-se por estudar, no presente trabalho, o baço quanto sua topografia, morfologia e irrigação, para que se compreenda melhor este órgão, que revela extrema importância para os profissionais que trabalham com ela, já que apresenta aspectos imunológicos e, principalmente, armazenamento de sangue.

\section{Material e Método}

Utilizou-se 20 tartarugas da espécie Trachemys scripta elegans, sendo oito machos jovens, seis machos adultos, duas fêmeas jovens e quatro fêmeas adultas, doadas pelo 
Departamento de Psicologia Experimental do Instituto de Psicologia da Universidade de São Paulo. O material foi descongelado em água corrente à temperatura ambiente. Em seguida, retirou-se o plastrão, visualizando a cavidade pleuroperitoneal. Uma vez isolado o coração, identificou-se a aorta comum, na sua emergência do órgão, onde os vasos que desembocam no coração foram pinçados, já na porção descendente da aorta, antes de sua bifurcação, uma cânula foi introduzida e fixada, por onde se injetou, primeiramente, água ligeiramente aquecida, com o objetivo de retirar possíveis restos de gelo presentes nas artérias. Posteriormente, injetou-se solução de látex (solução de látex retirada da Hevia brasilienses obtida na Usina de Beneficiamento de Látex Planalto Paulista, município de Buritama SP) corada com pigmento específico (Suvinil Corante, Glasurit do Brasil S.A.) para melhor identificar os vasos irrigantes.

Uma vez injetado todo o sistema, os animais foram colocados em recipiente

\begin{tabular}{|l|c|c|c|c|}
\hline & A.L & A.P.D.C. & A.C.E. & A.J. \\
\hline 1-macho adulto & $\mathrm{X}$ & $\mathrm{X}$ & - & - \\
\hline 2-macho jovem & $\mathrm{X}$ & $\mathrm{X}$ & - & - \\
\hline 3-macho jovem & $\mathrm{X}$ & $\mathrm{X}$ & - & $\mathrm{X}$ \\
\hline 4-macho jovem & $\mathrm{X}$ & $\mathrm{X}$ & - & - \\
\hline 5-fêmea adulta & $\mathrm{X}$ & - & - & $\mathrm{X}$ \\
\hline 6-macho adulto & $\mathrm{X}$ & - & $\mathrm{X}$ & - \\
\hline 7-macho adulto & $\mathrm{X}$ & - & - & - \\
\hline 8-fêmea jovem & $\mathrm{X}$ & - & $\mathrm{X}$ & - \\
\hline 9-fêmea adulta & $\mathrm{X}$ & - & $\mathrm{X}$ & - \\
\hline 10-macho adulto & $\mathrm{X}$ & - & $\mathrm{X}$ & - \\
\hline 11-macho jovem & $\mathrm{X}$ & - & $\mathrm{X}$ & - \\
\hline 12-macho jovem & $\mathrm{X}$ & - & - & - \\
\hline 13-fêmea jovem & - & - & $\mathrm{X}$ & - \\
\hline 14-fêmea adulta & $\mathrm{X}$ & - & - & - \\
\hline 15-macho jovem & $\mathrm{X}$ & - & $\mathrm{X}$ & - \\
\hline 16-macho jovem & $\mathrm{X}$ & - & $\mathrm{X}$ & - \\
\hline 17-macho jovem & $\mathrm{X}$ & - & $\mathrm{X}$ & - \\
\hline 18-fêmea adulta & $\mathrm{X}$ & - & - & - \\
\hline 19-macho adulto & $\mathrm{X}$ & - & - & - \\
\hline 20-macho adulto & $\mathrm{X}$ & - & - & - \\
\hline
\end{tabular}

Quadro 1 - Freqüência das artérias do baço em tartarugas (Trachemys scripta elegans) (A.L. - artéria lienal, A.P.D.C. - artéria pancreáticoduodenal cranial, A.C.E. - artéria cólica esquerda e A.J. - artérias jejunais)

contendo solução aquosa de formaldeído a $20 \%$, por período não inferior a 72 horas. Após a fixação, procedeu-se à dissecação dos vasos, que foram esquematizados, comparados os resultados e fotografados para documentação.
Com relação à nomenclatura utilizada, adotou-se a Nomina Anatômica Avium proposta por Baumels ${ }^{1}$, por não haver nomenclatura específica para quelônios, uma vez que, na escala evolutiva, os répteis assemelhamse muito mais às aves do que aos mamíferos. 


\section{Resultados}

Este capítulo será dividido em:

A - Morfologia do Baço

O baço apresentou-se com coloração vermelho escuro arroxeado ou até mesmo amarronzado, onde a forma variou de esferóide a elipsóide (Figuras 1 e 2).

\section{B - Topografia do Baço}

O baço localizou-se dorsalmente ao cólon transverso, disposto no plano dorsomédio-lateral esquerdo. Observamos em seis animais (30\%) o baço posicionado caudalmente ao cólon transverso, perdendo a intimidade com o ventrículo; e em quatorze animais $(70 \%)$, posicionado cranialmente ao cólon transverso, com grande contato com o ventrículo gástrico através do ligamento gastrolienal (Figuras 1 e 2).

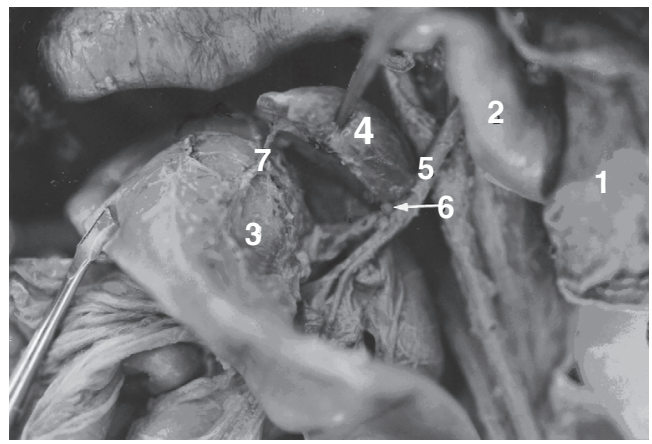

Figura 1- Fotografia da cavidade pleuroperitoneal de uma tartaruga (Trachemys scripta elegans), vista ventral, onde podemos notar o lobo hepático esquerdo (1), parte do ventrículo gástrico (2), o baço (4) sendo irrigado pela artéria lienal (6) que é proveniente da artéria mesentérica cranial (5) e de uma ramificação da artéria cólica esquerda (7), que irriga e percorre toda a extensão do cólon transverso (3)

\section{C - Irrigação do Baço:}

Grande parte da irrigação do baço é proveniente da artéria mesentérica cranial (95\% dos casos), pois, a artéria lienal, a artéria pancreáticoduodenal cranial e as artérias jejunais são ramificações da mesma. Apenas seis exemplares $(30 \%)$ apresentavam irrigação somente pela artéria lienal. Em oito exemplares $(40 \%)$, notamos que a irrigação era promovida pela artéria lienal e por pequenos ramos provenientes da artéria cólica esquerda.

Em apenas um caso (5\%), a irrigação do órgão era realizada pela artéria lienal e por um único ramo emitido por uma das artérias jejunais. Um animal (5\%) apresentou o baço sendo irrigado pela artéria lienal, por um ramo proveniente da artéria pancreáticoduodenal cranial e por uma artéria que tem origem no tronco comum das artérias jejunais; três casos (15\%) mostravam a irrigação do baço sendo promovida pela artéria lienal e por ramos emitidos pela artéria pancreáticoduodenal cranial. Em apenas um caso (5\%) observouse o órgão sendo irrigado apenas por pequenas ramificações arteriais provenientes da artéria cólica esquerda (Figuras 1 e 2).

\section{Discussão}

\section{A - Morfologia do Baço}

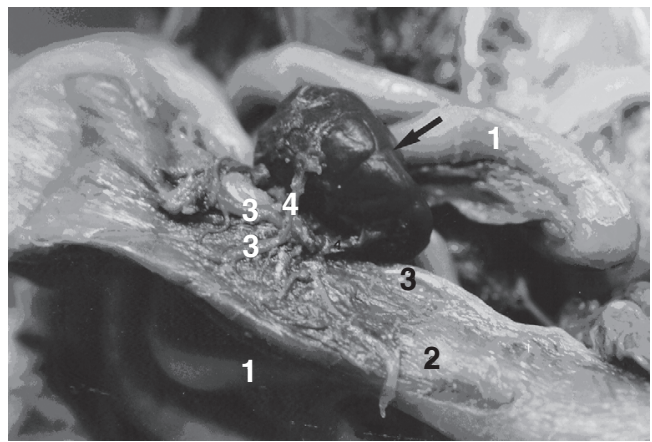

Figura 2- Fotografia da cavidade pleuroperitoneal de uma tartaruga (Trachemys scripta elegans), vista ventral, onde podemos observamos o jejuno (1) e o baço () sendo irrigado apenas pelos ramos (4) da artéria cólica esquerda (3), que percorre e irriga todo o cólon transverso (2)

As descrições de Dulzetto ${ }^{2}, \mathrm{Hyman}^{3}$, Mader ${ }^{4}$, Orr ${ }^{5}$, Pisanó e Barbieri ${ }^{6}$ e Zapata, Leceta e Barrutia ${ }^{7}$, foram confirmadas, relatando que o baço de tartarugas apresentase como um órgão vermelho escuro arroxeado ou até mesmo amarronzado. Contudo, sabe-se que técnicas de congelamento e fixação promovem alterações na coloração dos tecidos.

Com relação à forma do baço, observa-se que a mesma varia de esferóide a elipsóide, condizendo, em partes, com os 
relatos de Ashley $^{8}$, Dulzetto ${ }^{2}, \mathrm{Hyman}^{3}$ e $\mathrm{Mader}^{4}$, que o descrevem como uma glândula esferóide; e com os de Sayles ${ }^{9}$ e Zapata, Leceta e Barrutia et al. ${ }^{25}$, que o descrevem como um órgão oval. Assim como discorremos sobre a coloração do baço, a forma do tecido também pode ser alterada pelas técnicas de congelamento e fixação.

\section{B- Topografia do Baço}

$\mathrm{Baer}^{2}$, estudando répteis, notou que o baço localiza-se na superfície do epíplon e tem íntima relação com o ventrículo gástrico através do ligamento gastroesplênico. Da mesma forma, Sayles ${ }^{9}$, estudando tartarugas (Pseudemys), relatou a presença do baço sobre o cólon maior, sintópico ao ceco e apresentando contato direto com o ventrículo gástrico - ambos os relatos foram confirmados através do presente estudo, porém, em apenas $70 \%$ dos casos; o restante não tinha relação tão próxima com o ventrículo gástrico, devido ao seu deslocamento caudal. Zapata, Leceta e Barrutia $^{7}$ e Mader ${ }^{4}$ também descreveram a íntima relação do baço com a porção inferior esquerda do ventrículo gástrico. Baer ${ }^{10}$ relatou, ainda, que o baço posicionase junto à superfície ventral da cavidade, todavia, observamos sua presença sobre a parede dorsal do cólon transverso, coincidindo com relatos de Ashley ${ }^{8}$, Dulzetto $^{2}$, Hyman $^{3}$ e Sayles? .

Grassé $^{11}$ também descreveu que a localização do baço pode ser à esquerda e abaixo do ventrículo gástrico. $\mathrm{O}$ primeiro fator é confirmado, contudo, a segunda afirmação é parcialmente evidenciada, uma vez que se observou em $30 \%$ dos casos, a perda da intimidade do baço com o ventrículo gástrico.

Com relação aos achados de Firth e Turner $^{12}$, Leceta e Zapata ${ }^{13}$, Leceta e Zapata ${ }^{14}$ e Qiusheng e Qizhuo ${ }^{15}$, que realizaram estudos estabelecendo relações entre o período do ano/produção hormonal/ tamanho/localização do baço, não temos parâmetros para discutir, pois nossos estudos não foram executados com animais vivos.
Evidenciamos sim, o baço na topografia descrita, ou seja, localizado cranial ou caudalmente ao cólon transverso, mas não sabemos qual a fase hormonal que cada animal se encontrava no momento do óbito.

Orr ${ }^{5}$ declara que o baço de tartarugas está disposto cranialmente no abdome, deslocado à esquerda na cavidade peritoneal, sendo fato confirmado através deste trabalho.

\section{C- Irrigação do Baço}

Neste projeto científico evidenciaramse resultados bastante interessantes, uma vez que se observam grandes variações com relação à irrigação do baço em tartarugas da espécie Trachemys scripta elegans.

O relato de Thomson ${ }^{16}$, estudando quelônios, foi no presente estudo confirmado, uma vez que a artéria lienal é uma ramificação da aorta esquerda. Com relação à nomenclatura utilizada por este autor e também por Tanaka e Elsey ${ }^{17}$, que estudaram o baço de crocodilos (Alligator mississipiensis), preferiu-se o termo artéria lienal ao invés de artéria esplenoduodenal, por verificar-se que, na maioria dos casos, o baço e o duodeno não têm irrigação comum proveniente da artéria principal do baço, em tartarugas da espécie Trachemys scripta elegans.

As descrições de Noble e Noble ${ }^{18}$, analisando tartarugas aquáticas da espécie Clemmys marmorata, relatam que o suprimento sangüíneo do baço era promovido através de um ramo proveniente da artéria mesentérica cranial, que por sua vez provinha da aorta esquerda - relatos estes, que condizem com nossos achados.

Messer ${ }^{19}$ descreve o suprimento sangüíneo do baço de anfíbios do gênero Necturus através de ramificações da artéria gástrica. Notou-se que, em tartarugas, esta afirmação não é verdadeira, uma vez que observamos o baço sendo suprido por diversos ramos arteriais, provenientes de diversas outras artérias, além de não evidenciarmos a irrigação deste órgão pela artéria gástrica.

Ao contrário do que afirma Brelan ${ }^{20}$, em tartarugas, e Ashley ${ }^{8}$, nos répteis em geral, 
nas tartarugas estudadas, o baço não apresenta irrigação proveniente da artéria celíaca, mas sim das artérias mesentérica cranial e, em apenas um caso, da cólica esquerda; além de receber suprimento sangüíneo secundário de vários outros ramos arteriais.

Grassé ${ }^{11}$ relatou que, em cobras, o suprimento sangüíneo do baço é proveniente da artéria celíaca; já em crocodilos, este mesmo autor descreve que o baço é irrigado através da artéria gastro-esplênico-intestinal, que é uma ramificação do tronco celíaco mesentérico. Ambos os fatos são divergentes se comparados com as descrições do presente estudo, pois, nota-se que a maior parte do sangue que nutre o baço provém da artéria mesentérica cranial.

Zapata, Leceta e Barrutia ${ }^{7}$, estudando quelônios, e Tanaka e Hirahara ${ }^{17}$ estudando ofídios da espécie Elaphe climacophora, descreveram a presença de apenas um hilo para entrada da artéria lienal; fato que não se evidenciou no presente trabalho, devido à presença de ramificações desta própria artéria irrigando setores diferentes no baço e ramos provenientes de outras artérias adentrando ao órgão.

Romer e Parsons ${ }^{21}$ relataram a emissão de ramos da artéria pancreáticoduodenal caudal na irrigação do baço de répteis. Em nosso material observamos a emissão de ramos da artéria pancreáticoduodenal cranial ao baço de alguns animais.

Baumels ${ }^{1}$, em última edição da Nômina Anatomica Avium, a qual se seguiu, descreveu que a artéria lienal de gansos é usualmente originária de um tronco da artéria celíaca. Já em nossos estudos, observamos a ausência da artéria celíaca, sendo que a artéria lienal provém diretamente da artéria mesentérica cranial.

\section{Topography, morphology and the irrigation of the spleen in Trachemys scripta elegan, (WIED, 1838) apenas por ramos da artéria cólica esquerda.}

\section{Abstract}

This study was conduct using 20 turtles specie Trachemys scripta elegans, which 2 young females, 4 adults females, 8 young males
Hildebrand $^{22}$, em seus estudos com quelônios, relataram a presença da artéria celíaca. Contudo, não foi observada nos animais estudados no presente trabalho.

Faria $^{23}$, descrevendo a irrigação do baço do jabuti Geochelone carbonaria, notou que provinha da artéria celíaca. Contudo, poderia apresentar dois padrões de irrigação: em 50\% dos casos seria suprido através da artéria lienal e em outros 50\% seria irrigado pela artéria pancreáticoduodenal cranial, sendo que esta última irrigaria o órgão e o deixaria em sentido ao estômago e fígado. Já no presente trabalho, notou-se que o baço pode realmente apresentar-se nutrido pelas artérias acima citadas, mas não apenas por elas, como também por ramos da artéria cólica esquerda e das artérias jejunais.

Não foram encontrados relatos em nenhum dos autores consultados a respeito da artéria cólica esquerda irrigando o baço.

\section{Conclusões}

Baseado nos resultados julga-se poder concluir que:

1 - o baço localiza-se no plano dorsomédio-lateral esquerdo, cranial ou caudal ao cólon transverso;

2 - a maior parte do sangue que nutre o baço é proveniente da artéria mesentérica cranial, sendo que o mesmo pode ser irrigado somente pela artéria lienal; pela artéria lienal e pequenos ramos da artéria cólica esquerda; pela artéria lienal e por ramos emitidos por artérias jejunais; pela artéria lienal, por ramos da artéria pancreáticoduodenal cranial e por artérias originárias do tronco comum das artérias jejunais; pela artéria lienal e por ramos da artéria pancreáticoduodenal cranial; ou

Key words: Spleen. Trachemys scripta elegans. Topography. Morphology. Irrigation. 
and 6 adults males. Initially, it was took the hoof belly and, isolating the heart to identify more precisely the arteries was injected latex solution with red pigment through aorta descendens with one thin tube before aorta's bifurcation. After the latex injection, all the animals were submerged in $20 \%$ formaldeid water solution by a period of more than 72 hours. After that period, the arteries responsible by spleen irrigation were dissected. It was found in 30\% of the cases the spleen was positioned behind colon transversum; and in $70 \%$ in front of colon transversum. Regarding the spleen irrigation, it was observed in 100\% of the cases that arteria lienalis had its origin in arteria mesenterica cranialis. Which $30 \%$ had irrigation only by arteria lienalis. In $40 \%$ the irrigation was done by arteria lienalis and small branches of arteria colica sinistra. In $5 \%$ of the cases it was irrigated by arteria lienalis and by na unique branch sent by one of arteriae jejunales. In $5 \%$ of the cases the irrigation through arteria lienalis and by one branch of arteria pancreaticaduodenalis cranialis, and also by one artery with origin in the common trunk from arteriae jejunales. In 15\% from the animals, irrigation was done by arteria lienalis and by branches from arteria pancreaticaduodenalis cranialis. In $5 \%$ of the cases the spleen was irrigated just by ramifications of arteria colica sinistra.

\section{Referências}

1 BAUMEL, J. J. Handbook of avian anatomy: Nomina Anatomica Avium. 2. ed. Massachusetts: Nuttall Ornithological Club, 1993. p. 432.

2 DULZETTO, F. Anatomia comparata dei vertebrati. Bologna: Calderini, 1967. v. 1, p. 1180.

3 HYMAN, L. H. Comparative vertebrate anatomy. 2. ed. Chicago: The University of Chicago Press, 1942. p. 277.

4 MADER, D. R. Reptile medicine and surgery. Philadelphia: W.B. Saunders, 1996. p. 280.

5 ORR, R. T. Biologia dos vertebrados. 5. ed. São Paulo: Roca, 1999. p. 107-109.

6 PISANÓ, A.; BARBIERI, F. D. Anatomia comparada de los vertebrados. Buenos Aires: Rivadavia, 1967. p. 170-171, 200-201.

7 ZAPATA, A.; LECETA, J.; BARRUTIA, M. G. Ultrastructure of splenic with pulp of the turtle, Mauremys caspica. Cell and Tissue Research, n. 220, p. 845-855, 1981.

8 ASHLEY, L. M. Laboratory anatomy of the turtle. 6 . ed. Washington: College Place, 1969. p. 19-20, 30, 34 35 .

9 SAYLES, L. P. Manual for comparative anatomy. New
York: MacMillan, 1938. p. 144

10 BAER, J. G. Anatomie comparée des vertebrés. Suisse: Masson Griffer, 1965. p. 149.

11 GRASSÉ, P-P. Traité de zoologie. 6. ed. Paris: Masson, 1970. v. 4, t. 2, p. 457-458.

12 FIRTH, B. T.; TURNER, J. S. Sensory, neural, and hormonal thermoregulation. In: GANS, C.; $\mathrm{POUGH}$, F. H. Biology of the reptilia. 2. ed. Oxford: Academic Press, 1982. v. 12, p. 251.

13 LECETA, J.; ZAPATA, A. G. Seasonal changes in the thymus and spleen of turtle, Mauremys caspica. A morphometrical, light microscopical study. Dev. Comp. Immunol., v. 9, n. 4, p. 653-668, 1985.

14 LECETA, J.; ZAPATA, A. G. White pulp compartments in the spleen of the turtle Mauremys caspica. A lightmicroscopic, eletron-microscopic and immunohistochemical study. Cell and Tissue Research, v. 266, n. 3, p. 605-613, 1992.

15 QIUSHENG, C.; QIZHUO, N. Studies on the microscopic and submicroscopic structures of the spleen in the turtle, Trionyx sinensis. Nanjing Nongye Daxue Xuebao, v. 18, n. 4, p. 91-97, 1995.

16 THOMSON, J. S. The anatomy of the tortoise. Scientific Proceedings, n. 28, p. 405, 1932.

17 TANAKA, Y.; HIRAHARA, Y. Spleen of the snake (Elaphe climacophora) and intrasplenic vascular 
architecture. Journal of Morphology, v. 226, n. 2, p. 223-235, 1995

18 NOBLE, G. A.; NOBLE, E. R. Anatomy of the turtle. Califórnia: Stanford University Press, 1940. p. 1, 4, 16-18.

19 MESSER, H. M. An introduction to vertebrate anatomy. New York: The Macmillan, 1947. p. 305.

20 BRELAND, O. P. Manual of comparative anatomy. 2. ed. New York: McGraw-Hill Book, 1953.

21 ROMER, A. S.; PARSONS, T. S. Anatomia comparada dos vertebrados. 7. ed. São Paulo: Atheneu, 1985. p. 390.

22 HILDEBRAND, M. Análise da estrutura dos vertebrados. 2. ed. São Paulo: Atheneu, 1995. p. 274, 286-287.

23 FARIA, T. N. Descrição da origem, trajeto e número das principais artérias do jabuti Geochelone carbonaria. 2000. 42 f. Dissertação (mestrado em Anatomia dos Animais Domésticos) - Universidade de São Paulo, Faculdade de Medicina Veterinária e Zootecnia, São Paulo, 2000. 